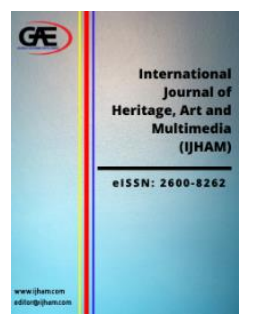

\author{
International Journal of Heritage, Art and \\ Multimedia (IJHAM) \\ Journal Website: http://ijham.com/ \\ eISSN: 2600-8262
}

\title{
IMPACTS OF SOCIAL MEDIA IN INFLUENCING PUBLIC OPINION IN THE MUSLIM COMMUNITIES
}

\author{
Adam Abdullahi Mohammed, $\mathrm{PhD}^{1 *}$, Ali Inusa ${ }^{2}$ \\ 1 Department of Islamic Studies, Yobe State University, Damaturu, Nigeria. \\ Email: adamnguru@gmail.com \\ 2 Department of Political Science, Yobe State University, Damaturu, Nigeria. \\ Email: aliinusa2016@gmail.com
}

\section{Article Info:}

Article history:

Received date: 15.02 .2020

Revised date: 19.02 .2020

Accepted date: 13.03.2020

Published date: 15.03.2020

\section{To cite this document:}

Mohammed, A. A., \& Inusa, A. (2020). Impacts of Social Media in Influencing Public Opinion in The Muslim Communities. International Journal of Heritage, Art and Multimedia, 3 (8), 28-39.

DOI: $10.35631 /$ IJHAM.38004.

\begin{abstract}
:
The paper examined the impacts of social media in influencing public opinion in Muslim communities. Invariably, public opinion is a vital tool for government, politicians, and decision-makers in all communities, including Muslims'. Social media is a powerful and strong machine to mold, shape, and influence public opinion. In developing this paper data were obtained from a secondary source, meaning data were generated from several documentaries such as- books, journals, newspapers, magazines, archives, etc. From the available literature, the study found that the mass media in general, and the social media in particular, are very important in making and influencing public opinion in the society, especially the Muslim communities. To explain the topic under study the researchers adopted two theories; culturists and Classdominant Theories. The theories claim that people interact with media to create their own meanings out of the images and messages they receive. This theory sees audiences as playing an active rather than a passive role in relation to social media. In addition, the assumption of these theories is that social media replicates and plans the view of a marginal elite, which controls the system to influence people's opinions. The researcher recommended that politicians, governments, and policymakers should pay much attention to social media and to use them wisely in a positive way, for their own good and for the benefit of their communities in particular and the society at large.
\end{abstract}

Keywords:

Impacts; Muslim Communities; Influencing; Public Opinion; Social Media 


\section{Introduction}

Social media is often advertised as an important influencer on public opinion and political causes (David, 2013). Social media has clearly changed how we receive and engage with information. But many complex questions remain about exactly what role it plays in shaping public discourse and its real impact on our perceptions of everything from electoral politics to policy debates (David, 2013). In addition, Social media in general, and twitter in particular definitely influence public opinion and decision makers. But on any given topic it can't be relied upon as a reflection of public opinion. Recent years have witnessed a dramatic change in the way people communicate, obtain and disseminate information. It is also noted that consumption of news from traditional media is deteriorating (Stempel, 2000). while online media has become an increasingly important source of information (Bialik, 2017). The key questions are how this communication and media revolution has influenced the flows of information across individuals and societies, and how one can influence these flows (Yuriy Gorodnichenko, Tho Pham, 2018).

Moreover, information and communication technology has changed rapidly over the past 20 years with a key development being the media. The pace of the change is accelerating. For example, the development of mobile technology has played an important role in modelling the impact of social media- across the globe. Mobile devices have taken over in terms of total minutes spent online. This puts the means to connect everywhere, at any time on any device in everyone's hands (Simplilearn, 2020).

The study of public opinion, and the influence of the social media in the Muslim communities has undergone through a lot of advancements up to this contemporary era, the era of rapid revolution of innovative technology. Therefore, the importance of public opinion has increased, its influence doubled and multiplied enthusiastically. This is because of the improvement of areas of communication, mass media and news casting. For instance in the last decades, with the advancement of technology, social media came into existence in different forms, such as Twitter, WhatsApp, Facebook etc. and they made great changes and impacts on public opinions in almost all societies (Gorodnichenko, Y, 2018).

For the aforementioned and other reasons, the researcher carried out this research in order to identify and highlight the manner in which these modern media make impacts on public opinion and the beginning of the media tradition in the Muslim community. This with the vies to be used positively in sanitizing the public opinion and redirecting it to look into issues of common interest properly, hence, to judge accordingly. For instance a man is not a social creature by his nature, every individual would have lived alone, and there would be no wisdom in making mankind of different races and tribes, and there would be no need for mutual acquaintance (al-ta`aruf) which depends on social ties. This social nature of human being necessitates him to interact with the people of his community, and the interaction, in turn, will compel him to communicate. There is no communication that can take place without means, therefore, through this communication via these means man forms his views and opinions, and consequently a public opinion will appear to dominate over a community.

According Plato Man is a social creature by nature, Muslims and non-Muslims are alike and are unable to dissociate themselves completely from others and live in isolation and seclusion. The Noble Qur'an testifies to this fact as the Almighty God, the Exalted says: "O mankind! We have created you males and females, and appointed you races and tribes, that you may know one another'. (Holy Qur'an, 49:13.) 


\section{Conceptualization of the Terms}

For proper understanding of the term social media, we need to know the concept of communication in general; because social media are part of communication. It is perceived by a lot of people that communication is only what we see and hear through mass media such as television, radio and newspapers, but actually communication means more than that. Communication can be defined as the transfer of information from one person to another, whether or not it elicits confidence. But the information transferred must be understandable to the receiver (Anjali, \& Emanuel, 2014). In the same vein, mass communication is defined as: "the process through which media organizations produce and transmit messages to large publics and the process by which those messages are sought, used, understood and influenced by audience". ("https://courses.lumenleaning.com/suny-introductiontocomunication," 2019).

\section{Public Opinion}

The subject of public opinion has been discussed from very remote time, even though it was not studied in a systematic and scientific method. It can be traced in the writings of Plato and Aristotle, though they did not define it technically. According to (Rafeeq, 1991) "public opinion is a social judgment of a self-conscious community on a question of general importance after rational discussion" Similarly, Murad al (2018) defined public opinion as "a unanimous judgment reached at by the people in a substantial given issue” (Rafeeq, 1991).

\section{Social Media}

All over the world, it is noted that the social media is making it easier for people to have a voice in government to share and discuss issues related to the communities and hold leaders responsible and accountable. For instance in 2011 social media played a precarious role in the Arab Spring in places like Tunisia, it was prefigured as a technology for freedom (Samidh, 2015).

The social media is a type of communication via internet, which billions of people globally use. For individuals it means a medium of communication with family and friends, and a means, also, of learning new things that enhance their skills, as well as having fun. For entrepreneurs it is a means of improving their entrepreneurship and enhancing their capabilities and professionalism. As for companies it is a means through which they can reach out their costumers and publicise their commercial advertisements (Bialik, 2017).

According to Samidh (2015) social media platforms are driving people not just to learn about issues but to take action. For instance, during the 2016 US election alone, it was estimated that the voter registration efforts on Facebook led more than 2 million people to register to vote. This has unveiled that social media has a significant effect in influencing people opinion in all communities.

More so, social media help in educating voters. Example during the last US election 2016, Voting Plan was created as a tool to preview local ballot and discuss it with friends. As a result of this millions of people did so and increased people's knowledge of their ballot by over $6 \%$. That's equivalent to raising the average ballot knowledge of the entire US Facebook community by a few grade levels.

Social media help people have a voice in their government every day, not just on Election Day. A study by (Samidh, 2015) disclosed that about $87 \%$ of governments around the world have a presence on Facebook. And they're listening and responding to what they hear. He further reveals that in Iceland, when someone moves to a new neighbourhood, the first thing to do 
often is to join their community's Facebook group. They tag their representatives in posts and push for the issues they want to take to policy makers as well as the Government. Discussions like these are quietly strengthening local governance around the world. This means that for the first time in history, people can keep up with their government as easily as they keep up with their friends. This is unlocking new waves of latent civic energy and putting power into more hands.

\section{"Social media is a computer-based technology that facilitates the sharing of ideas, thoughts and in origination as well as documents, photos and videos through the building of virtual networks and communities ("https://www.investopedia.com/terms/s/social-media.asp," 2019).}

Social media are some modern types of the traditional communications with advantages and preferences of low cost, easy to reach the masses of public opinion makers and the freedom in terms of time. Public opinion means the idea and opinion which the masses of public opinion makers unanimously arrived at, after series of discussions and deliberations then consensus on an important issue through any means of communication. It is not the mere opinion appears amongst the masses. The mass media in general, and the social media in particular, are very important in making impact and influence on public opinion. Especially, the social media works for all the aims and objectives of mass media which includes influencing the future of the masses.

\section{The Most Famous Types of Social Media}

Mass media is a significant force in modern culture, particularly in America. Sociologists refer to this as a mediated culture where the media reflects and creates the culture (Akua, 2019). Communities and individuals are bombarded constantly with messages from a multitude of sources including TV, billboards, and magazines, to name a few. These messages promote not only products, but moods, attitudes, and a sense of what is and is not important. Mass media makes possible the concept of celebrity: without the ability of movies, magazines, and news media to reach across thousands of miles, people could not become famous (Akua, 2019).

Social media include social networking applications such as Facebook and Google microblogging services such as Twitter, blogs, wikis, and media sharing sites such as YouTube and Flickr. Social media is considered to be a part of the Web 2.0 movement, which is characterized by user-generated content, online identity creation, and relational networking (Michael, 2012 p149). Social media can be accessed by computer, smart and cellular phones, and mobile phones text messaging (SMS). In addition to the above-mentioned ones, famous social media include Instagram, Snapchat, LinkedIn, WhatsApp, and Telegram.

\section{The Significance of Public Opinion}

Public opinion has a prime importance and significance, especially in political and governance studies. The importance can be put forward as follows: It is a means through which the public will participate with their opinions to enable the government to run its affairs wisely, and to control the masses. It's a means through which the government and decision makers solicit support from the masses, therefore the government and decision makers need to prevail on the public with adequate and necessary influence for them to get their support in foreign and internal policy making and other political decisions. The masses, nowadays, are more educated and aware of the public issues, and this in turn makes an obligation on governments and decision makers to seek the pleasure of the masses by giving them plain and right answers to their questions about public issues (Rafeeq, 1991p15). 


\section{Effect of Social Media in the Community}

However, social media was created to share information and to help in expressing public opinion. It further helps in assisting people to express themselves socially and politically. In doing this people should make sure that no one is bullied or threatened for their views and opinions (Samidh, 2015). He then added that, to make matters more complex, governments sometimes engage in such a harassment. It is noted that recently a citizen reported that after he had posted a video critical of the authorities, the police paid him a visit to inspect his tax compliance. In relation to this some countries write laws that attempt to outlaw online speech, the risk grows that states use their power to threaten their detractors. That could have a frightening effect on speech (Samidh, 2015). Similarly, it was observed that even in more open societies, we're seeing cases where government administrators write unbearable posts that make imposing our communal standards inspiring. So far, such post was kept up on platform since people view them as interesting information that citizens merit to know and explore. The study further found that these posts frequently become significant for counter speech, but it is noted and recognize that reasonable people may disagree with this policy. The major concern of this study is to ensure that political hate speech aren't limited to the online sphere there is need to be vigilant that the social media doesn't simplify offline ferocity (Samidh, 2015). According to (RuthAnne, 2016) the Social media has transformed the way people view themselves, the way they see others and the way they interact with the world. He then added that the social media has many positive effects, which include promoting awareness of a precise causes, advertising trades and helping foster relationships between individuals who may have never met without social interaction. Furthermore, the study found that the social media has a countless exciting improvement in technology and has greatly increased communication across cultures and positively brought attention to events around the world. This is in line with the culturist's theory which claims that people interact with media to create their own meanings out of the images and messages they receive. In view of this the theory sees viewers of the social media as playing an active rather than passive role in relation to mass media.

It is understood that in the past, looking for knowledge about Islam was mainly limited to the educational institutions, Masjids, and learning from imams and sheikhs. However, these traditional learning opportunities remain complete. however, now Muslims are also able to learn, question, teach, and network through social networking sites (Javeria, 2011).

"There are more avenues by which to learn about Islam. The Internet has
given the public access to all kinds of information and made Islamic
literature so much more accessible," said Fozi. On YouTube, for example,
you can listen to a lecture in any language you want, whenever you want.
Blogging sites such MuslimMatters.org and SuhaibWebb.com have
become extremely popular with both Muslims and non-Muslims as a way
to gain information and learn about Islam (Javeria, 2011)".

However, a study by Français (2019) exposed that high school programs are being promoted by the social media awareness and has become beneficial to the people in the society. He added that social media give students more understanding of how the media may affect them socially. For example, in Canada, the Media Awareness Network (MAN) has a number of resources that can be used by both specialists and the public to promote media literacy.

From the above view it is understood that, without social media, social, ethical, environmental and political ills would have minimal perceptibility. Increased visibility of issues has shifted 
the balance of power from the hands of a few to the masses. The flipside: Social media is slowly killing real activism and replacing it with 'slacktivism'. While social media activism brings an increased awareness about societal issues, questions remain as to whether this awareness is translating into real change. Some argue that social media has encouraged people to use computers and mobile phones to express their concerns on social issues without actually having to engage actively with campaigns in real life. Their support is limited to pressing the 'Like' button or sharing content (Simplilearn, 2020). In a related development a study by (Simplilearn, 2020) opined that one of the effects of social media is encouraging people to form and treasure artificial links over actual relationships. The term 'friend' as used on social media lacks the closeness branded with conservative relationships, where people really know each other, want to talk to each other, have an intimate bond and regularly interact face to face.

However, it is understood that parents may feel outwitted or astounded by their youths' computer and Internet capabilities, or they may not appreciate that the "new medium of communication' as an important element of the new knowledge, something in which their children need to be aware of and have confident on. These spirits of insufficiency or misconception should not prevent the parents from learning the Internet's aids (Français, 2019).

According to (Samidh, 2015), one of the most common criticisms of the social media is that it creates echo cavities where people only see viewpoints they agree with further driving people apart. He then added that, the legitimate issue is more complex than how it is sometimes portrayed. Compared with the media landscape of the past, social media exposes people to a more diverse range of views. A recent Reuters Institute Digital News Report found that $44 \%$ of people in the US who use social media for news end up seeing sources from both the left and the right more than twice the rate of people who don't use social media (Samidh, 2015).

A study by (Javeria, 2011) disclosed that in the post 9/11 era, the growth of electronic and, in particular, social media in general has had a significant impact on the lives of Muslims around the world. He further added that;

"Social media presents a huge opportunity the Muslims to reach out to people who may not know about Islam or Muslims. Thousands of Americans have never met a Muslim, but they have access to them through social media".

However, social media are almost free of charge media and one has absolute freedom of speech. There are other advantages of social media in making impact in originating public opinion, which make it more advantageous than the classical media. This includes:- relevancy; which means that the contents are relevant to the audience's level of civilization and their busy schedules; because they are, usually being presented in a form of short clips and brief articles. Obtainable at any time; unlike the Classic Media which are restricted to a given time, the social media can be accessed at any time (Reports, 2019)

\section{The Challenges of Social Media}

Several books, journals, articles and newspapers discussed the challenges of the social media in the communities. The social media has been blamed for encouraging and promoting social evils such as: 


\section{Cyberbullying}

It is noted that youths have a need to fit in, to be popular and to outdo others. This process was interesting long before the creation of social media. Such as Twitter, Instagram Facebook and Snap chat into the mix and unexpectedly adolescents are being subjected to feeling pressure to grow up too fast in an online charting (Jenny, 2016). In view of this (Michael, 2012) showcased that the effects of social media on bullying is $23 \%$ of teens report being targeted and 15 percent said they'd bullied someone on social media. Teenagers can misuse social media platforms to spread rumours, share videos aimed at destroying statuses and to intimidate others people (RuthAnne, 2016).

\section{Lack of Privacy}

In addition to the above it is understood that pestering, identity theft, personal attacks, and misuse of information are some of the threats faced by the users of social media. Most of the time, the users themselves are to blame as they end up sharing content that should not be in the public eye. The confusion arises from a lack of understanding of how the private and public elements of an online profile actually operate (Jenny, 2016).

In a related development a study by Stephanie (2012) lamented that despite the fact that anxiety- and anger-based messages were on the fringe between 2001 and 2008, the scientists add. However, the media's intense focus on organizations putting out negative messages seems to have strengthened those group's positions. He added that:

"There are consequences of this media coverage, so that fringe organizations can actually come to redefine what we think of as mainstream (Stephanie, 2012)".

For instance, after the terrorist attacks of Sept. 11, Bail became interested in the public discourse surrounding Islam. Disputes about the belief have frequently get up since 2001, including Florida pastor Terry Jones' promise to burn Korans in 2010, considered an insult in Islam, and a recent anti-Muslim film that prompted riots around the world (Stephanie, 2012).

A study by français (2019) showcased that television has the potential to create both positive and negative effects on the youth and children that are largely the dominant of the community. More so, many studies have observed the impact of television on community, particularly on children and youths. An individual child's developmental level is a critical factor in determining whether the medium will have positive or negative effects. However, not all media programs are bad, but some help in shaping, molding and influencing people opinion.

Similarly in a related development a study by Français (2019) unveiled that nowadays, television has become a leading sex educator in Canada. For instance, between 1976 and 1996, there has been a $270 \%$ increase in sexual interactions during the family hour of 2000 hours to 2100 hours. Television exposes children to adult sexual behaviours in ways that depict these actions as normal and risk-free, sending the message because these manners are frequent, 'everybody does it.

\section{Theoretical Framework}

There are many theories that would explain the impact of social media in the community. But for the purpose of this study the researchers adopted two theories to support the argument. The theories are culturists and Class-dominant theories. Culturists' theory: The culturists theory, 
developed in the 1980s and 1990s, claims that people interact with media to create their own meanings out of the images and messages they receive. This theory sees audiences as playing an active rather than passive role in relation to mass media. One component of research focuses on the impact of social media in the Muslim communities and how its influence people opinion in the society (Akua, 2019).

\section{Class-Dominant Theory}

The assumption of this theory is that social media replicates and plans the view of a marginal elite, which control it. Those people who own and control the establishments that produce media encompass the elite. Supporters of this view concern themselves particularly with massive corporate mergers of media organizations, which limit competition and put big business at the reins of media particularly news media. The belief of this theory is that when ownership is limited, few people have the capacity to operate what people can see or hear and response when the needs arises. For instance, proprietors can easily avoid or silence stories that picture immoral communal behaviour or hold companies accountable for their activities (Akua, 2019).

\section{The Muslim Community}

A study by (Javeria, 2011) exposed that Suzy Ismail believes that the media has played a crucial role in the way Muslims and Islam have been perceived over the years. He then explained that;

"It would be hard for anyone to say that they have not 'heard' of Islam with the amount of coverage that social media has received in recent years through so many different media channels. Nevertheless, because of media filters and biased reporting or media coverage, it's impossible to control the presentation of the deans to those who may not be familiar with the concepts and tenets of Islam."

He further added that since $9 / 11$

"Islam and Muslims have been both maligned and instantaneously maltreated. There seems to be two extreme reactions to the religion itself. One is sincere curiosity and interest that motivates education and the other is blind hatred and misunderstanding that leads to scapegoating and stereotyping."

"He narrated that media has been both a blessing and curse for Muslims and Islam. Because of the thorn in media's exposure of Islam in recent ages it has "definitely increased general alertness of the people belief".

The Muslim Community means a community whose constitution and legal system were derived from the Qur'an and Sunnah of Prophet Mohammad. And it is the community which its members share the same Islamic beliefs, in spite of their differences in terms of race, nation, language and tradition (Mish'al, 2018). However, in this research the Muslim Community means: that community whose traditions and costumes have their roots back to the Islamic teachings and the majority of its population are Muslims, even if the Islamic Law, its practice and procedure are not fully implemented (Al-Mutawakkil, 2014). 


\section{The Impact of Social Media in Influencing Public Opinion in Muslim Communities}

A new study from Pew Research claims that 62 percent of people get their news from social media, with 18 percent doing so very often. In comparison to other media, social media's influence in political campaigns has amplified immensely. Social networks play progressively significant role in democracy, first in the eventually unsuccessful candidacy of Howard Dean in 2003, and then in the election of the first African American president in 2008. Social media has had a philosophical effect on employment and appointment. 19 percent of hiring managers make their engagement decisions based on information found on social media.

According to CareerBuilder's 2016 social media recruitment survey, 60 percent of establishments use social networking sites to research job applicants (Simplilearn, 2020). He in addition, explained that almost a quarter of the world's population is now on Facebook. In the USA nearly $80 \%$ of all internet handlers are on this podium. Because social networks feed off interactions among people, they become more powerful as they grow day to day activities.

Mass media helps shape public opinion. It is a powerful force, yet many people do not realize what effect it has in shaping their opinion. Mass media is intended to be informative. Public opinion depends on knowledge about what is going on in the country and the world. The media provides the public with this knowledge through a variety of means: radio, print journalism, television and the Internet. Thus, the media makes national politics possible. Without mass media, candidates would only be able to run at the local level, where they could communicate personally with the electorate. Media makes it possible for voters to familiarize themselves with candidates and platforms even when they are far away (RuthAnne, 2016).

According to (Français, 2019) Television viewing regularly confines children's time for vibrant activities such as playing, reading, learning to talk, spending time with peers and family, storytelling, partaking in regular activities which include several programmes on Islam, and developing additional essential physical, mental and social skills. In addition to the amount of time spent in front of the television, other factors that influence the medium's effect on children include the child's developmental level, individual vulnerability and whether children watch television alone or with their parents. Things around human being, in any given community, make effect on him; at the same time, he also makes effect on them. This happens in form of competition, collaboration, controlling or fear etc. Undoubtedly, in different aspects of lives, be it educational, political or economic, people's opinions, their desires, decisions and reactions relate to the level of their civilization and the relationship they establish with the media.

The appearance of social media in Muslim communities creates a distinct relationship between the political system and the public opinion, and the reasons are as follow: Politicians and government officials use social media to advertise, promote and support their policies, projects and plans, so it is a channel that links between government officials, politicians and policy makers and the masses. Therefore, it inspires citizens to form a public opinion in their favor. Social media has become a means that Muslim youths use to reach to their people and inspire them to participate and make impact on societal events; as they don't have other means to do so (Seeny, 2015)

\section{Findings}

The study found that there are series of debate over the impact of social media in the Muslims community, and it seems to centre around two arguments: One camp argues that the social media opens new doorways for engaging the electorate and is creating pathways for greater 
civic engagement, corporate and political accountability, and journalistic integrity. The other claims the speed of information and individual selectiveness of what people choose to hear on social media impedes critical thought. In short, social media closes us off from differing viewpoints, and thus stifles any form of debate (David, 2013). However, it is observed that social media posts about current events, news, and social and political debates which actually shape people's opinions about those issues. The study further found that people see social media as an echo chamber of likeminded viewpoints, and it leads to the reinforcement of one's own beliefs about current social and political debates. More so, the social media is doing more than just changing the ways in which people consume news. Is it leading to greater awareness of important issues and current events? Thanks to the internet, each individual with peripheral views can see that he's not alone. And when these people find one another via social media, they can do things create memes, magazines and entire online worlds that strengthen their worldview, and then break into the mainstream. In a related development a study by Samidh (2015) disclosed that social media has enormous power to keep people informed. According to the Pew Research Centre, two-thirds of US adults consume at least some of their news on social media. Since many people depends upon news they weren't explicitly seeking out, the social media is often expanding the audience for news.

According to (Bialik, 2017)the mass media is informative. This means the public depends on knowledge about what is happening in the nation and the world at large. He disclosed that the social media provides the general public with knowledge through a variety of means such as: radio, print journalism, television and the Internet. Therefore, the media influence the public and makes national politics possible. Without mass media, contenders would only be able to participate at the local and national level, where they could communicate individually with the voters. Media makes it possible for electorates to acquaint themselves with candidates and platforms even when they are far away from the electorates.

\section{Recommendations}

$\checkmark$ It is recommended that the politicians and governments, especially in the Muslim communities, pay special attention to the social media and to use them wisely and in a positive way, so that they use them for their own good and to benefit their communities;

$\checkmark$ It is also recommended that the Muslims youths in the communities should be acquainted and familiar with the importance and advantages of the social media in making their voices heard; so that they will use it to impact on public opinion and hence to participate, indirectly, in decision making, so as to influence people opinion in the Muslim communities.

$\checkmark$ This study recommended the Muslim users of social media in Muslim communities to be very careful and cautious about the news, opinions, ideas and ideologies being published to instigate turmoil, unrest and confusion in the community, which is contrary to pristine teachings of Islam.

$\checkmark$ The paper recommended that the uses of the social media should engage in sharing religious doctrine that would help in moulding and sharpening people opinions.

$\checkmark$ It also recommended that all issues would course Muslims and Islam should be avoided.

$\checkmark$ Youth should avoid sharing religion issues that would course conflict among the general public.

$\checkmark$ The paper suggested that Muslims users of the social media should encourage their fellow members to share educative issues that would assist in influencing people opinion. 
$\checkmark$ Community's leaders should encourage the users of social media to share issues that are relevant in the society.

\section{Conclusion}

Since social media may create a sense of public consensus or support, social media could indeed affect public opinions in many ways. Explicitly, social bots could spread and intensify information therefore, influencing what humans think about a given issue and likely reinforcing humans' beliefs. Not unexpectedly, bots were used during the political campaigns people study to rejuvenate electorates and, according to the simple arithmetic, bots may have slightly donated to the results of several Muslim communities. The study at the end concluded that social media help in energising policy and decision makers across the world. Apparently, regulating information flows is an extremely delicate business in a democratic society characterised by diverse views and tolerance for this diversity. Though, cherishing diversity does not mean that one should allow the propagation of lies and manipulations to the extent that the public cannot make a well-informed decision. Where one should draw the line is an important question for the society.

\section{References}

Akua, G. (2019). Eight Ways We're Preparing for Elections Across Africa.

Al-Mutawakkil, M. A. (2014). "introduction to communication and public opinion" second edition, University of San'a. p 12\&14,.

Anjali H, \& Emanuel H. (2014). Role of professional communication in todays world of business and commerce, journal of research in humanities and social science, 2.

Bialik, K. and K. M. (2017). "Key trends in social and digital news media", Pew Research Center, 4 October.

David, C. (2013). Social Media's Influence on Public Discourse in the Pacific Northwest.

Français, V. (2019). Impact of media use on children and youth https://www.ncbi.nlm.nih.gov/pmc/journals/.

Gorodnichenko, Y, T. P. and O. T. (2018). "Social media, sentiment and public opinions: Evidence from \#Brexit and \#USElection", NBER working paper 24631.

Holy Qur'an. (n.d.). The Holy Qur'an, Surah 4:11.

https://courses.lumenleaning.com/suny-introductiontocomunication. (2019).

https://www.investopedia.com/terms/s/social-media.asp,. (2019).

Javeria, S. (2011). Impact of Media and Social Media on Islam and Muslims.

Jenny, H. (2016). Can Connected Health Change Your Practice?

Michael, J. M. (2012). A Review of Social Media Use in E-Government Journal of administrative science, 2012.

Mish'al. (2018). https://mawdoo3.com. last updated.

Murad al, S. (2018). https://mawdoo3.com,.

Rafeeq, S. (1991). Studies on public opinion, communication and advertisement , 1st edition, mu'min quraish bookshop, Tripoli, Lebanon.

Reports. (2019). www.gwf-online.org/reports/1248/،.

RuthAnne, S. (2016). Social Media's Impact On Society Stop staring at a screen all day!

Samidh, C. (2015). Hard Questions: What Effect Does Social Media Have on Democracy?

Seeny, S. A. (2015). "introduction to public opinion in Islamic perspective" p 29 -13, Al-Risala foundation.

Simplilearn. (2020). What Is the Major Impact of Social Media.

Stempel, G H, T. H. and J. P. B. (2000). "Relation of growth of use of the Internet to changes in media use from 1995 to 1999”, Journalism \& Mass Communication Quarterly 77(1): 71-79. 
Stephanie, P. (2012). Negative Portrayals of Muslims Get More Media Attention. www.yourarticlelibrary.com/essay/public-opinion retrieved. (2019).

Yuriy Gorodnichenko, Tho Pham, O. T. (2018). Social media, sentiment and public opinions: Evidence from Brexit and the USElection. 